\title{
Isolated Diastolic Hypertension among Adults in Saudi Arabia: Prevalence, Risk Factors, Predictors and Treatment. Results of a National Survey
}

\author{
Abdalla Abdelwahid Saeed, Nasser Abdulrahman Al-Hamdan
}

Background: In the past, diastolic hypertension was the main criterion for treatment, but currently, systolic pressure is the main criterion because it was thought that Isolated Diastolic Hypertension (IDH) is not associated with complications. Studies later revealed that IDH carries significant risks. Quantifying the magnitude and risk factors of IDH in the community is essential for all intervention strategies.

Aims: This study aims to determine the prevalence, risk factors, predictors, treatment modalities and lifestyle practices of IDH adult patients in the Kingdom of Saudi Arabia (KSA).

Study Design: Cross-sectional study.

Methods: A community-based cross-sectional study using STEPwise approach among adults using a multistage, stratified, cluster random sample was carried out. Data were collected using questionnaires which included socio-demographics, blood pressure, biochemical, anthropometric measurements and lifestyle practices. Sta- tistical analysis included calculating means and standard deviations, proportions, univariate and multiple logistic regression analysis.

Results: Of a total 4562 subjects, 180 (3.95\%) suffered from IDH, which was significantly related to age, gender, employment, smoking, diabetes mellitus, obesity and hypercholesterolemia. More than $93 \%$ were using some form of treatment, with $77.2 \%$ on prescribed drugs, $63 \%$ using diet, and $23 \%$ using exercise. Significant predictors of IDH were retirement and hypercholesterolemia. Conclusion: IDH is associated with some sociodemographic characteristics and co-morbidity. Given the risk of cardiovascular disease associated with IDH, the findings of this study emphasize the need for diagnosing the disease in middle-aged persons focusing on the modifiable risk factors of IDH.

Keywords: Adults, isolated diastolic hypertension, Saudi Arabia
Hypertension is a significant worldwide health problem, including the Kingdom of Saudi Arabia (KSA) (1-5). These problems are associated with both systolic blood pressure (SBP) and diastolic blood pressure (DBP) levels (6). Diastolic pressure was mostly the basis of clinical decisions but systolic blood pressure is thought to be more important, particularly among the elderly $(7,8)$. This has resulted in greater emphasis being placed on systolic blood pressure, and isolated systolic hypertension (ISH) has been identified as a specific clinical entity. Isolated Diastolic Hypertension (IDH) was not recognized as a separate entity and some authors think that one should not even bother measuring DBP (9). Although current guidelines from several authorities including the KSA call for treating hypertensives at levels $<140 / 85 \mathrm{mmHg}(10-12)$. Many studies, however, emphasized the importance and benefits of treating diastolic hypertension in young adults (7,13-17). It has been recommended by many authors that IDH should be monitored and affected persons should be managed targeting

Address for Correspondence: Dr. Abdalla Abdelwahid Saeed, Department of Community Medicine, King Saud bin Abdulaziz University of Health Faculty of Medicine, King Fahad Medical City, Riyadh, Saudi Arabia

Phone: 00966502469819 e-mail: saeed.abdalla@gmail.com

Received: 17.05.2015 Accepted: 16.09.2015 • DOI: 10.5152/balkanmedj.2015.153022

Available at www.balkanmedicaljournal.org

Saeed AA, Al-Hamdan NA. Isolated diastolic hypertension among adults in Saudi Arabia: Prevalence, risk factors, predictors and treatment. Results of a national survey. Balkan Med J 2016;33:52-7 
the control of all cardiovascular risk factors (18). Previous surveys in KSA reported a 5.3\% prevalence of IDH more than two decades ago (4). Studies in different countries reported a prevalence of IDH ranging from $2-8 \%$, mostly associated with males, younger adults, and obese individuals (19-24). In this study, we will assess the current prevalence of IDH, characteristics, treatment modalities, patient' practices, risk factors and significant predictors which were not previously addressed to the best of our knowledge. It is hoped that such data can be helpful in the overall strategy for the prevention and control of hypertension and cardiovascular diseases.

\section{MATERIALS AND METHODS}

This was a cross-sectional national community-based study covering the whole of the Kingdom of Saudi Arabia in 2005. The WHO STEPwise approach to Surveillance (STEPS) of Non Communicable Diseases (NCD) risk factors was the basis for conducting the survey and collecting data $(25,26)$. The study population were Saudi adults aged 15-64 years selected by a multistage stratified cluster random sampling technique. Stratification was based on age, gender and health regions of the country.

All primary health care centers (PHCCs) in each region were identified and listed and a $10 \%$ random sample was chosen. Households for each catchment area of each PHCC were identified and each house was given a number. A simple random sample was chosen from the households and selected households were visited for data collection. Data were collected by trained health care providers who were part of the health team in each PHCC. Data were collected using the standardized World Health Organization (WHO) questionnaire which was translated into Arabic and back-translated to ensure accuracy. The Arabic version was pilot tested for clarity and wordings of the questions. Questions related to alcohol use were not included in observations due to the religious and cultural norms of the community. The questionnaire include sociodemographic, health status, and lifestyle data, as well as anthropometric, biochemical and BP measurements. The measurements of BP were taken using a digital sphygmomanometer (OMRON B/P machine-digital automatic blood pressure monitor M4-1) following standardized procedures in subjects who rested quietly for five minutes with their legs uncrossed and their right arm unclothed. The appropriate cuff size was properly wrapped in the right arm placed on a table with the palm facing upwards. Pushing the 'START' button enabled the automatic inflation of the cuff and display of the reading of systolic blood pressure (SBP) and diastolic blood pressure (DBP) readings, which were recorded. A second reading was taken five minutes after the first and a third reading was taken five minutes after the second. The subject was labeled hypertensive if the average of the 3 blood pressure measurements was $140 \mathrm{mmHg}$ or above for systolic and/or 90mmhg or above for diastolic blood pressure. Isolated diastolic is when diastolic pressure is $90 \mathrm{mmHg}$ or above and systolic pressure is below $140 \mathrm{mmHg}$.

\section{Statistical analysis}

Collected data were checked and analyzed using the statistical software (SPSS Inc. Released 2008. SPSS Statistics for Windows, Version 17.0.; Chicago, IL, USA).

Descriptive statistics were used as follows: For quantitative variables, means and their related standard deviations, while qualitative variables were described in the form of frequency and percentages. The Chi-squared test was used to find any association between IDH and categories such as sociodemographic, lifestyle and comorbidity. Logistic regression analysis was used to determine predictors of IDH.

The study was approved by the Ministry of Health, Centre of Biomedical Ethics.

Informed consent of all subjects was obtained and confidentiality of data was assured.

\section{RESULTS}

A total of 4758 subjects participated in the study; 4562 were included in the final analysis giving an overall response rate of $95.9 \%$. The overall prevalence of hypertension was $20.9 \%$ (951 patients). Table 1 profiles the demographic characteristics along with the prevalence of IDH. Males constituted about $49 \%$ of the study population. About a quarter of the subjects were in the age group 35-44 years, with primary care education. The majority of employed subjects work as government employees. About one third of subjects earn less than 3000 Saudi Riyals (800 US \$). The prevalence of IDH was $3.95 \%$ (180 patients), constituting $18.9 \%$ of all hypertensives and about half of them ( 89 patients) were not aware of their disease; they discovered their illness for the first time during the survey. IDH was significantly associated with age, gender and occupation. It was significantly higher among males, in the age group 35-44 years and among government employees. IDH was not significantly associated with place, education or income. IDH was significantly higher among smokers, but it was not related to physical activity and diet, as shown in Table 2. Table 3 shows the prevalence of IDH according to some comorbidities. Isolated diastolic hypertension was significantly higher among obese subjects, as classified with BMI but not with central obesity and among hypercholesterolemic patients. Of the 91 known patients, $48.4 \%$ (44) were 
TABLE 1. Prevalence of Isolated Diastolic Hypertension according to the sociodemographic characteristics

\begin{tabular}{|c|c|c|c|c|}
\hline \multirow[t]{2}{*}{ Characteristic } & \multirow{2}{*}{$\frac{\text { Total }}{\mathrm{N}(\%)}$} & \multicolumn{3}{|c|}{ Hypertensives } \\
\hline & & Number & Percentage & $\mathrm{p}$ \\
\hline \multicolumn{5}{|l|}{ Gender } \\
\hline Male & $2232(48.9)$ & 113 & 5.1 & 0.001 \\
\hline Female & $2330(51.1)$ & 67 & 2.9 & \\
\hline \multicolumn{5}{|l|}{ Age (Years) } \\
\hline $15-24$ & $1015(22.2)$ & 28 & 2.8 & \\
\hline $25-34$ & 1075 (23.6) & 28 & 2.6 & \\
\hline $35-44$ & 1134 (24.9) & 69 & 6.1 & $<0.001$ \\
\hline $45-54$ & $810(17.8)$ & 40 & 4.9 & \\
\hline $55+$ & $528(11.6)$ & 15 & 2.8 & \\
\hline \multicolumn{5}{|l|}{ Education } \\
\hline Non & $1224(26.9)$ & 40 & 3.3 & \\
\hline Primary & $1159(25.5)$ & 48 & 4.1 & \\
\hline Intermediate & $721(15.8)$ & 25 & 3.5 & 0.226 \\
\hline Secondary & $707(16.2)$ & 31 & 4.2 & \\
\hline University & $692(13.0)$ & 33 & 5.6 & \\
\hline Vocational & $119(2.6)$ & 3 & 2.5 & \\
\hline \multicolumn{5}{|l|}{ Occupation } \\
\hline Government employee & $1320(29.0)$ & 72 & 5.5 & \\
\hline Non-government employee & $430(9.4)$ & 17 & 4.0 & \\
\hline Student & $615(13.5)$ & 18 & 2.9 & 0.026 \\
\hline Housekeeping & $1693(37.2)$ & 53 & 3.1 & \\
\hline Retired & $300(6.6)$ & 13 & 4.3 & \\
\hline Unemployed & $198(4.3)$ & 7 & 3.5 & \\
\hline \multicolumn{5}{|l|}{ Region } \\
\hline Central & $1098(24.1)$ & 51 & 4.6 & \\
\hline Eastern & $669(14.7)$ & 27 & 4.0 & \\
\hline Northern & $409(9.0)$ & 10 & 2.4 & 0.368 \\
\hline Western & $1371(31.2)$ & 52 & 3.7 & \\
\hline Southern & $963(21.1)$ & 40 & 4.2 & \\
\hline \multicolumn{5}{|l|}{ Family Income ( Saudi Riyals) } \\
\hline$<3000$ & $1446(33.4)$ & 55 & 3.8 & \\
\hline $3000-6999$ & $967(22.4)$ & 34 & 3.5 & \\
\hline $7000-9999$ & $1264(29.2)$ & 56 & 4.4 & 0.620 \\
\hline $10000-14999$ & $431(10.0)$ & 14 & 3.2 & \\
\hline $15000+$ & $216(5.0)$ & 11 & 5.1 & \\
\hline
\end{tabular}

not undergoing treatment. Of the patients who were under treatment (47), about $93 \%$ were under some form of treatment suggested by a health professional. These modalities included drugs, diet, weight loss, exercise and quitting smoking. No patient consulted a traditional healer or used herbal medicines, as shown in Table 4. There were no significant differences in these practices according to the sociodemographic character-
TABLE 2. Prevalence of Isolated Diastolic Hypertension according to some lifestyle practices

\begin{tabular}{lccc}
\hline Variable & Number & Percentage & $\mathrm{p}$ \\
\hline Physical Activity & & & \\
$\quad$ High & 26 & 3.6 & \\
$\quad$ Medium & 125 & 3.3 & 0.389 \\
$\quad$ Low & & & \\
Ever Smoking & 48 & 4.9 & 0.048 \\
$\quad$ Yes & 132 & 3.7 & \\
$\quad$ No & & & \\
Fruits and vegetable consumption & & 3.9 & 0.524 \\
$\quad$ Below 5 serves per day & 162 & 4.0 & \\
$\quad$ 5 + serves per day & 11 & & \\
\hline
\end{tabular}

TABLE 3. Prevalence of Isolated Diastolic Hypertension according to some comorbidities

\begin{tabular}{lccc}
\hline Variable & Number & Percentage & $\mathrm{p}$ \\
\hline Diabetes Mellitus & & & \\
$\quad$ Diabetic & 33 & 4.8 & 0.112 \\
$\quad$ Not diabetic & 142 & 3.7 & \\
Obesity (according to BMI) & & & \\
$\quad$ Obese BMI $\geq 30$ & 78 & 4.8 & 0.016 \\
$\quad$ Not obese & 99 & 3.4 & \\
Central Obesity: & & & \\
$\quad$ Yes & 39 & 4.1 & 0.527 \\
$\quad$ No & 138 & 4.1 & \\
Total cholesterol level & & & \\
Elevated $\geq 5.2 \mathrm{mmol} / \mathrm{L}$ & 52 & 6.1 & 0.001 \\
$\quad$ Not elevated & 119 & 3.3 & \\
High Density Lipoprotein & & & \\
Low $\leq 0.90$ mmol/L & 49 & 4.4 & 0.187 \\
$\quad$ High & 122 & 3.7 & \\
Low Density Lipoprotein & & & \\
Elevated $\geq 3.5 \mathrm{mmol} / \mathrm{L}$ & 59 & 4.5 & 0.065 \\
$\quad$ Not elevated & 105 & 3.5 & \\
\hline
\end{tabular}

BMI: body mass index; mmol/L: mille mole per liter; $\geq$ : equal to or more than; $\leq$ : equal to or less than

istics of subjects. All variables in the univariate analysis were analyzed again using multiple logistic regression for significant IDH predictors. Significant predictors for IDH were hypercholesterolemia and obesity, as depicted in Table 5.

\section{DISCUSSION}

The prevalence of IDH in KSA according to this study is $3.9 \%$ among adults aged $15-64$ years and $6.3 \%$ in the group 
aged $35-44$ years. It was $5.1 \%$ among adults over 30 years of age in a study two decades ago (4). Studies in other countries reported generally comparable prevalence rates among adults. The IDH prevalence was $4.5-6.7 \%$ in India $(19,20)$, about $6 \%$ in Ethiopia and Nigeria $(21,22)$, about $7.2 \%$ in Oman (23), 8.6\% in young adults in the USA (18) and 4.4\% in China (24). In this study, IDH was significantly more common among males, which is in agreement with many other studies. The group aged 35-44 years was the most affected age group in this study. Studies in other communities reported that IDH is more common in younger adults $(7,8,19,24,27)$. The significant association of IDH with obesity agrees with the findings of other studies $(19,28)$. The association of smoking with IDH in this study is not in agreement with other studies which revealed no significant association of smoking with IDH $(19,29)$. Smoking habits are self-expressed and are subject to bias recall. It is difficult to ascertain smoking status

TABLE 4. Treatment modalities and practices of patients with Isolated Diastolic Hypertension $(\mathrm{n}=47)$

\begin{tabular}{lcc}
\hline Variable & Number $*$ & Practicing *\% \\
\hline Any treatment & 24 & 51.1 \\
Prescribed drugs by physicians & 18 & 38.3 \\
Diet & 21 & 44.7 \\
Weight loss & 13 & 27.7 \\
Quit smoking & 3 & 6.4 \\
Exercise & 11 & 23.4 \\
Traditional healers & 0 & 0
\end{tabular}

*One patient can have more than one modality of treatment without biochemical confirmation. This may explain the inconsistency of smoking with IDH. This study revealed no significant association with the level of physical activity. Other studies reported a significant association with of IDH with physical inactivity. There was no significant association of nutritional habits and practice and IDH in this study. Retired subjects in this study showed the highest IDH prevalence. This may have been confounded with age and other factors including income, and psychological stress. About half of the patients with IDH were not aware of their condition in this study; the majority of those who were aware were not under treatment and many of those undergoing treatment were not properly controlled. Studies in many communities reported generally comparable finding for hypertensive patients. This calls for intervention strategies to detect patients early, and the treat them, aiming for proper control. This can help to reduce complications and mortality. The most prevalent lifestyle modality used by patients was dietary modifications in the form of low salt, physical exercise, weight reduction and quitting smoking. Such lifestyle modifications and others known as non-pharmacological or non-drug therapies are practiced by many hypertensive and normotensives worldwide. They are uniformly recommended by the KSA and international agencies for hypertension as treatment guidelines (9-11). We fully agree with the remark of authors of studies that if IDH is not considered a separate entity, then the medical profession may deny treatment to many who require it $(30,31)$. Not only treatment but also preventive and control measures targeting modifiable risk factors of IDH might be of greater public health importance (19) This study showed

TABLE 5. Multiple logistic regression for significant predictors of Isolated Diastolic Hypertension

\begin{tabular}{|c|c|c|c|c|c|c|c|}
\hline \multirow[b]{2}{*}{ Predictor } & \multirow[b]{2}{*}{ B } & \multirow[b]{2}{*}{ S.E. } & \multirow[b]{2}{*}{ Wald } & \multirow[b]{2}{*}{$\mathrm{p}$} & \multirow[b]{2}{*}{ Odds Ratio } & \multicolumn{2}{|c|}{ *95\% CI Odds Ratio } \\
\hline & & & & & & Lower & Upper \\
\hline Region & $-0.383-$ & 0.294 & 1.700 & 0.192 & 0.682 & 0.383 & 1.213 \\
\hline Gender & 0.284 & 0.239 & 1.415 & 0.234 & 1.328 & 0.832 & 2.121 \\
\hline Age & 0.002 & 0.010 & 0.051 & 0.821 & 1.002 & 0.983 & 1.022 \\
\hline Occupation & 0.104 & 0.069 & 2.268 & 0.132 & 1.109 & 0.969 & 1.269 \\
\hline Income & 0.000 & 0.000 & 0.303 & 0.582 & 1.000 & 1.000 & 1.000 \\
\hline Smoking & $-0.010-$ & 0.303 & 0.001 & 0.975 & 0.990 & 0.547 & 1.795 \\
\hline Diet & 0.676 & 1.034 & 0.427 & 0.513 & 1.966 & 0.259 & 14.909 \\
\hline Physical Activity & $-0.109-$ & 0.139 & 0.610 & 0.435 & 0.897 & 0.683 & 1.179 \\
\hline Obesity (BMI) & $-0.222-$ & 0.112 & 3.917 & 0.048 & 0.801 & 0.643 & 0.998 \\
\hline Central Obesity & 0.042 & 0.260 & 0.026 & 0.872 & 1.043 & 0.626 & 1.737 \\
\hline Total Cholesterol & $-0.205-$ & 0.081 & 6.376 & 0.012 & 0.815 & 0.695 & 0.955 \\
\hline Triglycerides & $-0.110-$ & 0.091 & 1.468 & 0.226 & 0.895 & 0.749 & 1.071 \\
\hline Diabetes Mellitus & $-0.290-$ & 0.245 & 1.400 & 0.237 & 0.748 & 0.462 & 1.210 \\
\hline Constant & 4.339 & 1.520 & 8.152 & 0.004 & 76.620 & & \\
\hline
\end{tabular}

CI: confidence interval; BMI: body mass index; B: natural log of the adjusted odds ratio; S.E.: standard error of B; Wald: Z-score test of sginificance of each predictor 
that IDH is associated with some sociodemographic characteristics such as gender and age and co-morbidity including obesity, diabetes and dyslipidemia. This emphasizes the need for diagnosing the disease in middle-aged persons particularly for male gender focusing on the modifiable risk factors of IDH including weight reduction, dietary factors and other lifestyle modifications.

\section{Study limitations}

The study is a cross-sectional design, mostly reflecting associations between IDH and its risk factors, and causation cannot be properly evaluated. Some data are recalled by subjects, so recall bias is expected.

Ethics Committee Approval: Ethics committee approval was received for this study from the Institutional Review Board, Ministry of Health, Centre of Biomedical Ethics.

Informed Consent: Written informed consent was obtained from household leaders who participated in this study.

Peer-review: Externally peer-reviewed.

Author contributions: Concept - A.S., N.H.; Design - A.S., N.H.; Supervision - A.S., N.H.; Resource - A.S., N.H.; Materials - A.S., N.H.; Data Collection \&/or Processing - A.S., N.H.; Analysis \&/or Interpretation - A.S., N.H.; Literature Search - A.S.; Writing - A.S., N.H.; Critical Reviews - A.S., N.H.

Acknowledgements: Authors would like to thank to Ministry of Health for their contributon.

Conflict of Interest: No conflict of interest was declared by the authors.

Financial Disclosure: The authors declared that this study has received no financial support.

\section{REFERENCES}

1. Kearney PM, Whelton M, Reynolds K, Muntner P, Whelton PK, He J. Global burden of hypertension: analysis of worldwide data. Lancet 2005;365:217-23. [CrossRef]

2. Wang H, Dwyer-Lindgren L, Lofgren K, Rajaratnam JK, Marcus JR, Levin-Rector A, et al. Age-specific and sex-specific mortality in 187 countries, 1970-2010: a systematic analysis for the Global Burden of Disease Study 2010. Lancet 2012;380:207194. [CrossRef]

3. El Bcheraoui C, Memish ZA, Tuffaha M, Daoud F, Robinson M, Jaber S, et al. Hypertension and Its Associated Risk Factors in the Kingdom of Saudi Arabia, 2013: A National Survey. Int J Hypertens 2014;2014:564679. [CrossRef]
4. Al-Nozha MM, Abdullah M, Arafah MR, Khalil MZ, Khan NB, Al-Mazrou YY, et al. Hypertension in Saudi Arabia. Saudi Med J 2007;28:77-84.

5. Bromfield S, Muntner P. High blood pressure: the leading global burden of disease risk factor and the need for worldwide prevention programs. Curr Hypertens Rep 2013;15:134-6. [CrossRef]

6. Kannel WB. Role of blood pressure in cardiovascular morbidity and mortality. Prog Cardiovasc Dis 1974;27:5. [CrossRef]

7. Franklin SS, Pio JR, Wong ND, Larson MG, Leip EP, Vasan RS, et al. Predictors of new-onset diastolic and systolic hypertension: the Framingham Hear Study. Circulation 2005;111:1121-7. [CrossRef]

8. Franklin SS, Milagros JJ Wong ND, L'Italien GJ, Lapuerta P. Predominance of isolated systolic hypertension among middleaged and elderly US hypertensives: analysis based on National Health and Nutrition Examination Survey (NHANESIII). Hypertension 2001;37:869-74. [CrossRef]

9 Sever P. Abandoning Diastole. BMJ 1999;318:1773-6. [CrossRef]

10 Saudi Hypertension Management Guidelines. National Commission for Hypertension \& Saudi Hypertension Management Group 2007, KSA.

11. Whitworth JA; World Health Organization, International Society of Hypertension Writing Group. 2003 World Health Organization (WHO)/International Society of Hypertension (ISH) statement on management of hypertension. J Hypertens 2003;21:1983-92. [CrossRef]

12. Campbell N, Kaczorowski J, Lewanczuk R, Feldman R, Poirier L, Kwong M, et al; Canadian Hypertension Education Program. 2010 Canadian Hypertension Education Program (CHEP) recommendations: the scientific summary - an update of the 2010 theme and the science behind new CHEP recommendations. Can J Cardiol 2010;26:236-40. [CrossRef]

13. Swales JD. Systolic versus diastolic pressure: paradigm shift or cycle? J Hum Hypertens 2000;14:477-9.

14. Hozawa A, Ohkubo T, Nagai K, Kikuya M, Matsubara M, Tsuji I, et al. Prognosis of isolated systolic and isolated diastolic hypertension as assessed by self-measurement of blood pressure at home - the Ohasama study. Arch Intern Med 2000;160:3301-6. [CrossRef]

15 Veterans Administration Cooperative Study on Antihypertensive Agents: Effects of treatment on morbidity in hypertension. 1. Results in patients with diastolic blood pressures averaging 115 through $129 \mathrm{~mm} \mathrm{Hg.} \mathrm{JAMA} \mathrm{1967;202:1028.}$

16. Arima H, Anderson C, Omae T, Woodward M, Hata J, Murakami Y, et al. PROGRESS Collaborative Group. Effects of blood pressure lowering on major vascular events among patients with isolated diastolic hypertension. the perindopril protection against recurrent stroke study (PROGRESS) trial. Stroke 2011; 42:2339-41. [CrossRef]

17. Arima H, Murakami Y, Lam TH, Kim HC, Ueshima H, Woo J, et al; Asia Pacific Cohort Studies Collaboration. Effects of Prehypertension and Hypertension Subtype on Cardiovascular Disease in the Asia-Pacific Region. Hypertension 2012;59:1118-23. [CrossRef] 
18. Beevers DG. Epidemiological, pathophysiological and clinical significance of systolic, diastolic and pulse pressure. J Hum Hypertens 2004;18:531e533.

19. Midha T, Lalchandani A, Nath B, Kumari R, Pandey U. Prevalence of isolated diastolic hypertension and associated risk factors among adults in Kanpur, India. Indian Heart J 2012;64:3749. [CrossRef]

20. Biswas M, Manna CK. Prevalence of hypertension and sociodemographic factors within the Scheduled Caste community of the District Nadia, West Bengal, India. High Blood Press Cardiovasc Prev 2011;18:179-85. [CrossRef]

21. Tesfaye F, Byass P, Wall S. Population based prevalence of high blood pressure among adults in Addis Ababa: uncovering a silent epidemic. BMC Cardiovasc Disord 2009;9:39. [CrossRef]

22. Asekun-Olarinmoye E, Akinwusi P, Adebimpe W,Isawumi M, Hassan M, Olowe O, Makanjuola O, et al .Prevalence of hypertension in the rural adult population of Osun State, southwestern Nigeria. Int J Gen Med 2013;6:317-22. [CrossRef]

23. Al Riyami A, Elaty MA, Morsi M, Al Kharusi H, Al Shukaily W, Jaju S. Oman World Health Survey: Part 1 - Methodology, Sociodemographic Profile and Epidemiology of Non-Communicable Diseases in Oman. Oman Med J 2012;27:425-43.
24. Huang J, Wildman RP, Gu D, Muntner P, Su S, He J. Prevalence of isolated systolic and isolated diastolic hypertension subtypes in China. Am J Hypertens 2004;17:955-62. [CrossRef]

25. Bonita R, de Courten M, Dwyer T, Jamorzik K, Winkelmann R. Surveillance of risk factors for Non Communicable diseases. The WHO Stepwise approach: WHO, 2001.

26. STEPwise WHO.http://.www.who.int/chp/steps/2005_Saudi Arabia_STEPS_Report_EN.pdf

27. Rapsomaniki E, Timmis A, George J, Pujades-Rodriguez M, Shah A, Denaxas S, et al. Blood pressure and incidence of twelve cardiovascular diseases: lifetime risks, healthy life-years lost, and age-specific associations in 1.25 million people. Lancet 2014;383:1899-911. [CrossRef]

28. Primatesta P, Falaschetti E, Gupta S, Marmot MG, Poulter NR. Association between smoking and blood pressure: evidence from the health survey for England. Hypertension 2001;37:187-93. [CrossRef]

29. Chirinos JA, Franklin SS, Townsend RR, Rajj L. Body mass index and hypertension hemodynamic subtypes in the adult US population. Arch Intern Med 2009;169-80.[CrossRef]

30. Tin LL, Beevers DG, Lip GY. Systolic vs diastolic blood pressure and the burden of hypertension. J Hum Hypertens 2002;16:14750. [CrossRef]

31. Luna RL, Luna LC. Is diastolic pressure losing its clinical usefulness? Arq Bras Cardiol 2007;89:e19-21. 